\title{
As doenças 'do trabalho' no Brasil no contexto das políticas públicas voltadas ao trabalhador (1920-1950)
}

\author{
Anna Beatriz de Sá Almeida*
}

Resumo: o artigo tem como tema central a história das doenças do trabalho no Brasil (1920-1950), analisada no âmbito da história do trabalho e das políticas públicas voltadas ao trabalhador. Serão enfocadas as condições de trabalho e saúde dos trabalhadores desde a virada do século XIX para o século XX e, em especial, a partir de 1930, com o governo Vargas e as políticas voltadas ao mundo do trabalho. Enfocaremos a história das doenças do trabalho e da medicina do trabalho no Brasil, no período de 1920 a 1950, destacando os variados grupos sociais que participaram desse processo (trabalhadores, médicos, servidores públicos, juristas, juízes, peritos, empresários, sindicalistas). Era necessário definir quais seriam as doenças consideradas como decorrentes do trabalho, definições essas que foram sendo modificadas ao longo do processo histórico, sempre permeadas pelos interesses e reivindicações dos grupos sociais envolvidos. Além de debates e artigos médicos, serão analisados exemplos de processos indenizatórios os quais acatavam ou não a reivindicação dos trabalhadores e seus familiares de que a tuberculose fosse considerada uma doença decorrente do trabalho.

Palavras-chave: história da doença do trabalho; história da tuberculose; história social do trabalho.

Abstract: this article is about the history of work-related diseases in Brazil (19201950) in the context of the history of work and public policies created to the workers. It will be focused on working conditions and health of the workers from the turn of the 19th century to the 20th century and specially from 1930, with Getúlio Vargas regime politics of work. We will analyze the history of work-related diseases and medicine in Brazil, in the period from 1920 to 1950, highlighting the numerous social groups (workers, businessmen, physicians, experts, judges, lawyers ...) who engaged in this process. Political powers, social and economic issues and medical knowledge interacted with the most diverse cultural traditions. It was necessary to define what would be considered as "work-related diseases", these definitions that have been modified along the historical process, always permeated by the

* Doutora em História pela Universidade Federal Fluminense (UFF). Pesquisadora e historiadora do Departamento de Pesquisa em História das Ciências e da Saúde da Casa de Oswaldo Cruz, Fundação Oswaldo Cruz (DEPES/COC/Fiocruz). 
interests and demands from the social groups involved. In addition to debates and medical supplies, we will analyse examples of compensation procedures which decided for or against the worker's claims and their families that tuberculosis was disease resulting from the work.

Keywords: history of work diseases; history of tuberculosis; history of social work.

(...) as percepções humanas do sofrimento e suas causas mudam historicamente junto com a capacidade de lidar com a miséria, capacidade esta que reflete recursos culturais, sociais e tecnológicos específicos. ${ }^{1}$

Seguindo na linha de argumentação de Barrington Moore, a exteriorização da ideia da doença para além do indivíduo, relacionando-a com as condições de trabalho, foi parte do processo de percepção/formulação da ideia da própria doença como uma "injustiça causada" que aumentava a miséria humana, mas que era um fato social e não um dado "natural". ${ }^{2}$ Eram determinadas condições de trabalho que causavam essas doenças e, portanto, elas eram passíveis de serem evitadas e, quando não o fossem, os trabalhadores acometidos pelas mesmas deveriam ser "indenizados".

É neste sentido que buscamos trabalhar com o processo de constituição dos saberes direcionados ao binômio saúde/doença do trabalho. O fato das "doenças do trabalho" e das condições de trabalho se tornarem objeto de políticas nos aponta para um processo anterior de sua desnaturalização e de criação de demandas que buscavam evitá-las ou compensá-las. Nas palavras de Marcelo Badaró Mattos, as diferentes formas de ação, as possíveis fragmentações, os tipos de conquistas, as formas de luta, em resumo, a diversidade dos mundos do trabalho, só podem ser compreendidas tendo por base as condições históricas nas quais as mesmas se deram:

(...) sem perder de vista os complexos caminhos de definição da subjetividade coletiva das classes sociais, ou seja, incluindo a diversidade de projetos societários que tais diferentes formas de exploração podem gerar, atentando para sua tendência a unificação, que só pode se completar em movimentos históricos nos quais o aspecto da organização e do espontaneísmo se complementem de forma bem sucedida. ${ }^{3}$

Em outras palavras, é a percepção, compartilhada por atores políticos diferenciados, de que tais doenças são uma "injustiça" e não um destino que queremos aqui ressaltar.

A civilização atual multiplica as possibilidades industriais e cria a cada instante novas formas de trabalho. [...] no uso de qualquer simples utensílio da vida quotidiana nós ignoramos a soma de esforço anônimo que nele se concretizou. Nem sempre esse esforço é dado sem outro ônus além da fadiga; muitas vezes no objeto que contemplamos e de que usamos prazerosos, está uma parcela invisível da saúde do anônimo

MOORE, Barrington. Injustiça - as bases sociais da obediência e da revolta. São Paulo: Brasiliense, 1987, p. 30. 2 MATTOS, Marcelo Badaró. "A classe trabalhadora através do materialismo histórico: passado e presente de um detalhe aberto". Relações Laborais em Portugal e no Mundo Lusofônico: História e Demografia. Lisboa, Edições Colibri, 2014, p. 219.

3 NASCIMENTO, Amauri Mascarro. Curso de Direito do Trabalho: história e teoria geral do Direito do Trabalho. Relações individuais e coletivas do trabalho. São Paulo: Editora Saraiva, 1989, capítulo I - História do Direito do Trabalho. 
trabalhador, que lentamente conquistou com o pão quotidiano a morbidez que o há de matar. ${ }^{4}$

Em 1917, o deputado trabalhista, Maurício de Lacerda, apresentou uma série de projetos dedicados à regulação das condições de trabalho propondo a criação do Departamento Nacional do Trabalho, o estabelecimento da jornada de oito horas, a criação de juntas de conciliação e arbitragem e a fixação de normas para o trabalho de mulheres e menores, entre outras medidas. ${ }^{5}$ Os meses de junho e julho daquele ano foram um marco no debate da questão social na Câmara, dada a concentração de projetos apresentados nesta linha em um contexto de grande pressão dos trabalhadores. Segundo Gomes:

Estes são os meses da maior mobilização de massas operárias até então verificada no Brasil: a greve paulista de 1917. Não, igualmente por acaso que a discussão da lei de acidentes de trabalho, projeto do senador paulista Adolpho Gordo, de 1915, abandonada por cerca de dois anos, foi retomada. ${ }^{6}$

Frente ao projeto de Maurício de Lacerda e outros, um antigo projeto do senador Adolpho Gordo de $1915^{7}$ foi retomado em 1917/1918, sendo revisto por uma Comissão Especial de Legislação Social que o dividiu em duas partes: uma sobre acidentes e outra sobre regulamentação do trabalho. O projeto da comissão para o tema dos acidentes do trabalho foi aprovado quase sem alterações pela Câmara e pelo Senado, tendo resultado na Lei $n^{\circ}$ 3.724, de 15 de janeiro de 1919, a primeira lei de acidentes do trabalho no país. Como destacamos acima era um contexto de pressão das classes trabalhadoras e das classes empresariais, ${ }^{8}$ sendo que coube às últimas a não votação do Projeto de Código do Trabalho e a sanção do que os mesmos julgavam pertinente da referida Lei de Acidentes do Trabalho. A conjuntura era de grandes manifestações operárias no Rio de Janeiro, tais como a Greve Geral de 1917, o Tratado de Versalhes de 1919 e o impacto da catástrofe do incêndio do New York Hotel, que estava em construção e dizimou centenas de trabalhadores. ${ }^{9}$

A saúde pública também fora um tema da agenda política do país ao longo dos anos de 1910 e $1920,{ }^{10}$ movimentando diversos grupos e instituições no debate sobre os rumos da saúde no Brasil. Os relatórios das expedições científicas do Instituto Oswaldo Cruz, a criação da Liga Pró-Saneamento do Brasil, a avassaladora epidemia de gripe espanhola de 1918 foram importantes acontecimentos que possibilitaram que a proposta de reforma dos serviços de saúde ganhasse mais força e representatividade no cenário nacional. ${ }^{11}$ O projeto da criação de um novo

4 Trecho do discurso do deputado Maurício de Medeiros apud AZEVEDO, Camerino Bragança de. "Doenças Profissionais em Geral”. (Tese apresentada à Faculdade de Medicina do Rio de Janeiro, sl. 1927).

5 NASCIMENTO. Curso de Direito do Trabalho. Capítulo I - História do Direito do Trabalho.

6 GOMES, Angela M. de Castro. Burguesia e Trabalho: política e legislação social no Brasil, 1917-1937. Rio de Janeiro: Editora Campus, 1979, p. 65.

7 Em 1915, o senador Adolpho Gordo apresentou um projeto sobre regulamentação do trabalho que ficou sem tramitar.

8 A proposição de pagamento de pensão aos acidentados foi alvo de críticas do Centro Industrial do Rio de Janeiro que defendia a indenização por uma só quantia, crítica esta que recebera o apoio de muitos industriais entre os quais Jorge Street. Cf. Jornal do Commercio, 07 de julho de 1917 - Seção Publicações e Pedidos.

9 GOMES. Burguesia e Trabalho, p. 65 e p. 66.

10 HOCHMAN, Gilberto. A Era do Saneamento. As bases da política de saúde pública no Brasil. São Paulo: Editora HUCITEC/ANPOCS, 1998, p. 111.

11 HOCHMAN. A Era do Saneamento, p. 138. 
ministério encontrou resistências na Comissão de Saúde Pública do Congresso, acirrando o debate acerca da centralização e descentralização dos serviços e da atuação do Poder Legislativo e dos poderes locais. O debate acabou conduzindo os deputados a concordarem com a criação de um novo órgão federal com mais poderes do que a existente Diretoria Geral de Saúde Pública, mas ainda sem o status de Ministério: o Departamento Nacional de Saúde Pública (DNSP), instituído em 1920 e regulamentado em $1923 .^{12}$

Acerca do tema da medicina e das doenças do trabalho, na proposta aprovada constava a atividade de "polícia sanitária das fábricas e oficinas". Com a regulamentação de 1923 do DNSP, foi instituída a Inspetoria de Higiene Industrial e Profissional. ${ }^{13}$ Esboçava-se assim a constituição de um setor e de possíveis políticas e ações mais específicas. Entre as atividades de sua competência, destacavam-se: o licenciamento e a autorização de transferência dos estabelecimentos industriais e oficinas; as visitas às fábricas e oficinas, inspecionando os locais de trabalho e os operários; a promoção do afastamento dos operários acometidos por lepra, tuberculose e qualquer outra doença infecto-contagiante; a responsabilidade pela análise das substâncias usadas nas indústrias; a adoção de medidas voltadas à proteção da saúde dos operários e dos moradores das vizinhanças dos estabelecimentos. ${ }^{14}$

A Lei de Acidentes do Trabalho de 1919 e a criação da Inspetoria de Profilaxia Industrial demonstram uma dada atuação do Estado, no final da década de 1910 e ao longo dos anos 1920, no âmbito da saúde e das doenças relacionadas ao mundo do trabalho. Porém, cabe destacar que, foi no decorrer dos anos de 1930 e 40, e em especial, após a instituição do Ministério do Trabalho, Indústria e Comércio (MTIC) em 1930, que se elaboraram políticas e ações mais efetivas no campo da saúde e segurança no mundo do trabalho. Como parte integrante desse processo de centralização político-administrativa e de intervenção do Estado, que associava valores materiais e simbólicos na busca de consenso social, as ações no campo do direito do trabalho, higiene e medicina do trabalho eram peças articuladoras da proposta de regulamentação de conflitos sociais pelo Estado Novo. ${ }^{15}$

O primeiro governo Vargas foi marcado por um conjunto de ações (leis, agências etc.) no campo das políticas sociais buscando legitimar o novo Estado e criar o novo cidadão/trabalhador responsável pelo desenvolvimento e crescimento harmônico da nova nação. No alvo preferencial de atenção e de políticas estava a criança, e mais especificamente, a criança trabalhadora, na medida em que ela era este cidadão/trabalhador do futuro, sendo, portanto, fundamental proteger e garantir o seu desenvolvimento. ${ }^{16}$

A doutrina do Estado Novo propõe todo o poder necessário ao Estado, visto como única instituição capaz de garantir a coesã o nacional e de realizar o bem público, para além dos interesses reais, mas mesquinhos dos indivíduos e dos grupos. Desenvolve, também, a crença no homem

12 HOCHMAN. A Era do Saneamento, p. 143.

13 Brasil. Coleção de Leis do Brasil, 31/12/1923, p. 581.

14 Brasil. Coleção de Leis do Brasil, 31/12/1923, p. 581.

15 Cf. GOMES, Angela M. de Castro. A Invenção do Trabalhismo. São Paulo: Vértice; Rio de Janeiro: IUPERJ, 1988; MATTOS, Marcelo Badaró. “'Trabalho e Seguro Social': Aspectos Médico-Higienistas da Política Social do Estado entre as Décadas de 1930 e 1950 no Brasil”. Rio de Janeiro, 1991 (mimeo).

16 Para maiores considerações sobre este tema ver FONSECA, Cristina M. Oliveira. "Modelando a "cera virgem': a saúde da criança na política social de Vargas”. (Dissertação de Mestrado em História, Universidade Federal Fluminense, 1990) e SOUSA, Cynthia Pereira de. "Saúde, educação e trabalho de crianças e jovens: a política social de Getúlio Vargas”. In: GOMES, Angela M. de Castro. Capanema: o ministro e seu ministério. Rio de Janeiro: Editora da FGV, 2000, p. 221-250. 
excepcional, portador de virtú, como o único capaz de expressar e construir a nova ordem. ${ }^{17}$

Neste contexto, foram instituídos o Ministério da Educação e da Saúde Pública $^{18}$ e o já referido MTIC, entre outras instituições voltadas para as políticas sociais priorizadas pelo novo governo. As políticas sociais criadas eram apresentadas como frutos e benesses deste novo projeto de nação, desvinculando-as de qualquer processo histórico social anterior de reivindicações e de diagnósticos da necessidade das mesmas. Nos estudos sobre a formulação de uma política social no Brasil, destacam-se as primeiras experiências de legislação social e de debates sobre o papel do Estado frente à questão social durante a República Velha e a pressão dos movimentos das classes trabalhadoras, mas o período pós-30 é consensualmente considerado um marco na incorporação definitiva da política social enquanto função do Estado - chave para a análise da política social do pós-30: "[...] são cidadãos todos aqueles membros da comunidade que se encontram localizados em qualquer uma das ocupações reconhecidas e definidas em lei". ${ }^{19}$ A estes cidadãos são dirigidas as políticas sociais no âmbito do trabalho e da previdência. O trabalho passa a ser o meio de o homem atingir a riqueza e a cidadania, sendo responsável pelo progresso do país. Ao analisar as relações entre Estado, patronato e trabalhadores, Gomes destaca que

... a constituição de uma legislação social está no cerne das relações capital/trabalho, tanto na órbita da sociedade civil, o que coloca o problema das relações diretas patronato/trabalhadores, quanto na órbita do próprio Estado, que vai assumindo papel cada vez mais destacado na questão, colocando-se como um terceiro elemento decisivo, com o qual cada um dos outros terá que entrar em contato, isoladamente ou não. ${ }^{20}$

A criação do MTIC, em 1930, e a implementação de todo um conjunto de leis sociais são referências exemplares da incorporação da política social enquanto função do Estado. O Estado pós-30 é analisado pela autora enquanto um Estado cujos objetivos políticos são a promoção do bem-estar nacional e a realização do bem comum, tendo a harmonia e a paz social como elementos constitutivos do ideal desse Estado. ${ }^{21}$

Instituído o MTIC fazia-se necessário muni-lo de quadros técnicos funcionais que o capacitasse a desempenhar suas funções, entre as quais, produzir a legislação social atinente à nova ordem que se implantava.22 Segundo Araújo, "socialistas, liberais, conservadores, técnicos, industriais, produzem uma legislação social acima do antagonismo das classes. Passo a passo alimentam a intervenção do Estado". ${ }^{23}$ Um dos caminhos pelo qual o Estado pós-30 enfrentou a questão social

17 OLIVEIRA, Lúcia Lippi. “Introdução”. In: OLIVEIRA, L. L.; VELLOSO, M. P. e GOMES, A. M. C. Estado Novo: Ideologia e Poder. Rio de Janeiro: Zahar Editores S.A., 1982, p. 24.

18 O Ministério da Educação e Saúde Pública foi criado pelo Decreto n 19.402 de 14/11/1930 e na Reforma de 1937, Lei n 378 de 13/01/1937, passou a denominar-se Ministério da Educação e Saúde.

19 SANTOS, Wanderley Guilherme dos. Cidadania e Justiça: a Política Social na Ordem Brasileira. Rio de Janeiro: Editora Campus, 1987, p. 68.

20 GOMES. Burguesia e Trabalho, p. 23.

21 GOMES. A Invenção do Trabalhismo, p. 222.

22 LEOPOLDI, Maria Antonieta P. "Estratégias de ação empresarial em conjunturas de mudança política”. In: PANDOLFI, Dulce (org.). Repensando o Estado Novo. Rio de Janeiro: Editora da FGV, 1999, p. 115-178. Este texto é bastante interessante também com suas considerações sobre o papel dos corpos técnicos nas novas agências e políticas governamentais.

23 ARAÚJO, Rosa Maria Barboza de. O Batismo do Trabalho: a experiência de Lindolfo Collor. Rio de Janeiro: Editora Civilização Brasileira, 1981, p. 68. Deste conjunto podemos destacar a indicação de Affonso Toledo Bandeira de Mello, Joaquim Pimenta e Evaristo de Moraes bem como de técnicos ligados à Organização 
foi a elaboração de leis de proteção ao trabalhador que, para além de regular as condições de trabalho - protegendo o trabalhador no seu físico e na sua moral dignificassem o cidadão-trabalhador, eliminando o seu sentimento de inferioridade e subordinação e enaltecendo o princípio da colaboração.

No conjunto maior da obra de construção do trabalhador nacional e de "revisão moralizadora" do conceito de trabalho, tem espaço e vai sendo construído o campo da medicina do trabalho. Cuidar da saúde do trabalhador nacional, e por extensão da sua família, é cuidar da nação, do conjunto da nacionalidade. Desta forma os trabalhadores vão sendo "diagnosticados no seu dia a dia, clinicados através de dispositivos que permitam a sua regeneração física e moral". ${ }^{24}$

A área da saúde do trabalho pode ser tomada como um campo de destaque no conjunto das políticas de valorização do trabalhador e do universo do trabalho no pós-30 e em especial ao longo do Estado Novo. Era fundamental desenvolver o aparato técnico especializado (médicos, juristas, economistas...) capaz de elaborar as normas e regulamentações nesse campo até então pouco privilegiado. Caberia a estes inspetores médicos do trabalho fiscalizar, realizar inquéritos e pesquisas sobre condições de trabalho, acidentes e doenças profissionais, tornando-se assim, de certa forma, especialistas em higiene e medicina do trabalho. A constituição deste grupo, os médicos do trabalho, só pode ser compreendida se inserida na análise do processo histórico de formação da nova burocracia de Estado no Brasil, no pós-30. Seria esta nova burocracia do Estado, a portadora de um discurso de competência técnica, fundamental à nova relação que se estabelecia entre o Estado e a sociedade:

A política do governo Vargas não procurava apenas resolver questões jurídicas e formais, mas interpretava os novos problemas econômicos e sociais dos tempos modernos, munida de administração e técnica especializadas. (...) As funções dos governos modernos são, acima de tudo, funções de especialização técnica, donde a importância da criação dos órgãos representativos da vida econômica do país podem, como interlocutores válidos, exprimir a vontade popular. ${ }^{25}$ (grifos nossos)

Tão logo fora criado, o MTIC passara a receber relatórios e reivindicações de diversos segmentos da classe trabalhadora nacional, dentre os quais Araújo destaca um memorial enviado por operários de fábricas de tecidos que, em meio à solicitação de melhoria salarial, regulação do horário de trabalho e outros pontos, reivindicavam tanto a higienização e a fiscalização sanitária das fábricas bem como, a reforma da Lei de Acidentes do Trabalho de 1919.

Em 1930, a já referida Inspetoria de Profilaxia Industrial, integrante do Departamento Nacional de Saúde Pública, passou, junto com o Departamento, à esfera do recém-criado Ministério da Educação e Saúde Pública, mas, com a criação do MTIC, em novembro de 1930, a Inspetoria de Higiene Industrial e Profissional foi transferida para o mesmo. No ano seguinte à criação do MTIC, em 1931, foi criado o Departamento Nacional do Trabalho (DNT), com uma seção voltada à organização, higiene e segurança do trabalho, que seria transformada anos depois em uma inspetoria. De acordo com o Relatório de Atividades do MTIC de 1934, a Inspetoria do Trabalho fora criada, em 1933, com a nomeação do inspetor chefe e a transferência para o DNT dos fiscais da lei de nacionalização. Porém, somente

Internacional do Trabalho, conhecedores da legislação trabalhista europeia e de estudiosos do Direito Social. 24 LENHARO, Alcir. Sacralização da Política. São Paulo: Papirus, 1986, p. 100.

25 GOMES, Angela M. de Castro. "O redescobrimento do Brasil”. In: OLIVEIRA, VELLOSO e GOMES. Estado Novo, p. 121 e p. 139. 
após a promulgação do regulamento do DNT, começaria o funcionamento normal da inspetoria como órgão de fiscalização das leis trabalhistas. ${ }^{26}$ Neste momento, foram nomeados os três primeiros "médicos do trabalho" com a função de inspecionar as fábricas, fazer inquéritos sobre condições de trabalho e pesquisas sobre moléstias profissionais.

Segundo o regulamento do DNT, caberia à Inspetoria do Trabalho: zelar pela fiel aplicação das leis e prescrições oficiais relativas à regulamentação, higiene e segurança do trabalho nos estabelecimentos e nas explorações; fazer inquéritos sobre as condições gerais de trabalho e realizar pesquisas sobre as moléstias profissionais, propondo medidas de proteção ao trabalhador; zelar pelo fiel cumprimento das leis e regulamentos relativos à organização e regulamentação do trabalho nos estabelecimentos industriais e comerciais. ${ }^{27}$ Assim, seria de responsabilidade da inspetoria, aplicar as leis e fiscalizar as condições de higiene e segurança do trabalho, bem como elaborar inquéritos e propor medidas de proteção à saúde do trabalhador. Inúmeros artigos publicados à época analisam a atuação do governo neste campo, dentre os quais destacamos o seguinte:

... nenhuma obra é mais meritória do que essa do atual governo em higienizar as fábricas tornando-as um ambiente salutar de trabalho. Quando se procura, por todos os modos, dar uma assistência social ao trabalhador, seria mesmo incompreensível que não se cuidasse da sua saúde, que o deixasse à margem de quaisquer cuidados e interesses profiláticos. $^{28}$

Ao relatar as atividades da Inspetoria do Trabalho ao longo de 1934, o diretor Dr. Luis Franco, argumenta acerca da necessidade de maiores investimentos na organização da mesma com o objetivo de realizar as suas atividades com maior êxito, em menos tempo e com um nível menor de dificuldades. Observa também o diretor que a experiência da inspetoria deveria ser objeto de atenção por parte daqueles que elaboram as leis e os regulamentos, enfatizando a necessidade da criação de um setor técnico com condições de responder adequadamente a todas as solicitações recebidas.

(...) Ainda recentemente teve esta inspetoria de resolver sobre uma consulta a respeito de emprego de uma substância química, - o flúor -, e opinar sobre o serviço de curtumes, lançando mão dos conhecimentos especializados dos Drs. Edison Cavalcante e Zey Bueno. ${ }^{29}$ (grifo nosso)

A fala do Dr. Luis Franco nos dá indícios acerca da luta pelo reconhecimento da importância da inspetoria, decorrente disso o pedido de mudanças na estrutura do serviço e também do papel dos especialistas - os técnicos em higiene industrial e engenharia - no cotidiano das atividades do setor, como ressaltou ao falar dos

26 Brasil. Relatório do MTIC de 1934 (Dr. Agamenon Magalhães). Rio de Janeiro: Departamento de Estatística e Publicidade, 1935.

27 Cf. Decreto $n^{\circ} 24.692$ de 12 de julho de 1934. Coleção das Leis do Brasil, 31/12/1934, p. 824. Regulamento do DNT: “Artigo 43 - Incumbe aos inspetores técnicos zelar pela fiel aplicação das leis e prescrições oficiais relativas à regulamentação, higiene e segurança do trabalho nos estabelecimentos e nas explorações onde são ocupadas pessoas assalariadas de ambos os sexos. Artigo 44 - Compete aos inspetores técnicos, além de suas incumbências com referência à fiscalização, fazer inquéritos sobre as condições gerais de trabalho e realizar pesquisas sobre moléstias profissionais, propondo medidas de proteção e prevenção em defesa dos trabalhadores".

28 CALLAGE, Fernando. "A Questão Social e a Cultura Brasileira”. Revista do Trabalho, 7(12), dezembro, 1939, p. 1.

29 FRANCO, Luis. “Relatório de Atividades da Inspetoria do Trabalho de 1934”. In: BMTIC, nº 7, março, 1935, p. 116. 
médicos Edison Cavalcante e Zey Bueno. ${ }^{30}$ Destaca-se assim o papel atribuído aos inspetores técnicos, como sendo especialistas responsáveis pela aplicação e cumprimento das leis bem como pela elaboração de inquéritos e estudos sobre proteção ao trabalhador e sobre moléstias profissionais, na medida em que a inspetoria recebia diversas consultas sobre o uso de produtos químicos e os seus efeitos na saúde dos operários, sobre a questão da exposição constante ao frio, ao calor, à umidade, sobre os prejuízos e os impedimentos do uso de mão de obra infantil e feminina em determinadas atividades, entre inúmeras outras questões.

Ao concluir o seu relatório, o Dr. Luis Franco tece considerações sobre o papel da inspetoria e do próprio MTIC de atuarem como mediadores entre grupos com interesses muitas vezes antagônicos. Esse reconhecimento não era o comum à época, visto que sempre era destacado o princípio da harmonia entre as classes e não se falava acerca do antagonismo entre as mesmas:

Pode contar esta seção com providências prontas e eficazes do atual titular da pasta do trabalho, para quem a fiscalização das leis sociais não deve ser um simples simulacro para abafar os protestos das classes trabalhadoras, mas a ação real e intensiva tendente a impedir que a legislação do trabalho se transforme em ilusória promessa, distante da realidade. (...) Concluindo, é licito esperar que, postas em prática as medidas que de certo não tardarão no sentido de reorganizar e desenvolver a inspetoria, poderá o Ministério do Trabalho, apesar de discutida a sua ação na luta incessante entre os antagônicos desejos e aspirações de empregados e empregadores, ter a serena consciência de haver cumprido a sua elevada missão. ${ }^{31}$

O tom da fala do diretor da Inspetoria do Trabalho nos permite inferir que o cotidiano das atividades da mesma deixava, como era de se esperar, bastante evidente as disputas, as resistências e os diferentes interesses de empregados e empregadores, sendo, portanto mais difícil ocultar tal realidade no corpo do relatório. A regulamentação das atividades do Ministério do Trabalho ocorreu paralelamente à elaboração e à promulgação da Constituição de 16 de julho de 1934. Esta previa, no Artigo 121 do Título IV - Da Ordem Econômica e Social, os princípios que iriam nortear a legislação do trabalho:

Art. 121 - A lei promoverá o amparo da produção e estabelecerá as condições do trabalho, na cidade e nos campos, tendo em vista a proteção social do trabalhador e os interesses econômicos do País. $\S 1^{\circ}$ - A legislação do trabalho observará os seguintes preceitos, além de outros que colimem melhorar as condições do trabalhador: a) proibição de diferença de salário para um mesmo trabalho, por motivo de idade, sexo, nacionalidade ou estado civil; b) salário mínimo, capaz de satisfazer, conforme as condições de cada região, às necessidades normais do trabalhador; c) trabalho diário não excedente de oito horas, reduzíveis, mas só prorrogáveis nos casos previstos em lei; d) proibição de trabalho a menores de 14 anos; de trabalho noturno a menores de 16 e em indústrias insalubres, a menores de 18 anos e a mulheres; e) repouso hebdomadário, de preferência aos domingos;

30 No artigo "Higiene do Trabalho", Revista do Trabalho, 7(5), maio, 1939, o Dr. Fernando Callage, do Instituto de Direito Social de São Paulo, destaca a importância da existência de efetivas leis de fiscalização das condições de trabalho: "É verdade que no Brasil já possuímos uma legislação bastante copiosa sobre a matéria, mas pouco se tem cumprido, legalmente, pela falta de controle, com as disposições da lei, daí, necessariamente, o dever social e cristão de um órgão fiscalizador, razão porque o governo pensa em criar uma lei de fiscalização da higiene do trabalho, tendo já sido elaborado, por uma comissão de médicos higienistas, um projeto de lei sobre a matéria" (p. 198).

31 FRANCO, Luis. "Relatório de Atividades da Inspetoria do Trabalho de 1934", p. 118. 
f) férias anuais remuneradas; g) indenização ao trabalhador dispensado sem justa causa; h) assistência médica e sanitária ao trabalhador e à gestante, assegurando a esta descanso antes e depois do parto, sem prejuízo do salário e do emprego, e instituição de previdência, mediante contribuição igual da União, do empregador e do empregado, a favor da velhice, da invalidez, da maternidade e nos casos de acidentes de trabalho ou de morte; i) regulamentação do exercício de todas as profissões; j) reconhecimento das convenções coletivas, de trabalho. ${ }^{32}$

O advento do Estado Novo em 1937 deve ser compreendido levando-se em conta as transformações que estavam ocorrendo no mundo, as quais reforçavam a ideia de que a democracia liberal estava acabada. Mas isto não quer dizer que o regime que ora se instalava no país seria uma cópia dos modelos fascistas europeus, deixando de lado as especificidades que caracterizariam o caso brasileiro. 0 governo centralizador e autoritário retirou do Poder Legislativo suas antigas atribuições, centrando no Executivo as tomadas de decisões e deliberações sobre a vida nacional. ${ }^{33}$ Analisando a Constituição de 1937 no tocante à legislação do trabalho, especificamente sobre questão dos acidentes, conservava-se a mesma indicação prevista na Constituição de 1934: a instituição de seguros de velhice, de invalidez e para casos de acidentes do trabalho. ${ }^{34}$ Em artigo publicado em 1938, Lysandro Monteiro de Resende avalia o impacto da nova constituição no âmbito do mundo do trabalho e tece o seguinte comentário:

[...] pela Constituição, a intervenção do Estado na economia individual só se dará e será legitima para suprir as deficiências da iniciativa individual e para coordenar os fatores da produção, a fim de evitar ou resolver os conflitos que os mesmos possam provocar, no alto intuito de se deslocar o jogo das competições individuais, muitas vezes nocivas à coletividade, para o ambiente dos interesses nacionais, mais amplo e isento de paixões. ${ }^{35}$

Em 1938, foi criado o Serviço de Higiene Industrial junto à Inspetoria do Trabalho. Era uma demonstração da necessidade de ampliar o espaço para as atividades no campo da higiene e da medicina do trabalho. ${ }^{36}$ Entre as atribuições do referido serviço, destacavam-se as atividades de fiscalização das leis e convenções relativas à higiene e segurança do trabalho, tais como: dar pareceres sobre os acordos e convenções coletivas de trabalho para as indústrias; fiscalizar e proibir certos tipos de atividades às mulheres e aos menores; realizar exames periódicos de saúde nos trabalhadores de indústrias frias; fazer inquéritos sobre as condições de trabalho e realizar pesquisas sobre moléstias profissionais. ${ }^{37}$

Pela análise destas atribuições, destaca-se a fiscalização das condições de trabalho tanto de mulheres e menores, bem como a realização de inquéritos nos

32 Cf. Brasil. Diário Oficial da União. Seção 1. Suplemento, 16/07/1934. Constituição de 1934, Título IV, Art. 121.

33 Há uma extensa bibliografia que trabalha com este período, da qual podemos destacar: OLIVEIRA; VELLOSO; GOMES. Estado Novo; MEDEIROS, Jarbas. Ideologia Autoritária no Brasil: 1930/1945. Rio de Janeiro: Editora da FGV, 1978; GOMES. A invenção do trabalhismo; BASTOS, Pedro Paulo Zahluth \& FONSECA, Pedro Cezar Dutra. (orgs.) A Era Vargas: desenvolvimentismo, economia e sociedade. São Paulo: Editora da UNESP, 2012.

34 Cf. Diário Oficial da União. Seção 1. 10/11/1937, p. 22359. "Constituição de 1937”, Título da Ordem Econômica, artigo 137.

35 REZENDE, Lysandro Monteiro de. "A Legislação do Trabalho em Face da Nova Constituição". Revista do Trabalho, Janeiro, 1938, p. 9.

36 Cabe lembrar que esta era uma das reivindicações do Inspetor do Trabalho, Dr. Luis Franco quando do seu Relatório de Atividades de 1934, trabalhado por nós anteriormente.

37 Portaria do Inspetor-Chefe do DNT de 27 de julho de 1938. 
estabelecimentos e de pesquisas sobre moléstias profissionais. Reforçava-se, tal como era previsto no regulamento do Departamento Nacional do Trabalho, de 1934, o caminho para inspecionar/conhecer "tecnicamente", em especial, através de inquéritos e pesquisas, a realidade das nossas fábricas e estabelecimentos industriais, realidade esta que já vinha sendo alvo de reclamações dos trabalhadores desde o início do século.

O campo da saúde do trabalho abrangia uma vasta área do universo das políticas sociais no período examinado. No conjunto das políticas e legislação social voltado (ou voltadas) para a saúde do trabalhador (medicina e higiene do trabalho), podemos distinguir dois grupos de medidas que se relacionam entre si. O primeiro reúne as medidas voltadas para a manutenção da saúde do trabalhador no processo de produção, via regulamentação das condições de trabalho. 0 segundo, as normatizações de caráter compensatório à perda da saúde, sendo assim medidas que atingem, na sua maioria, trabalhadores fora do mercado de produção.

Ao longo dos anos 30, 40 e 50 do século XX, a questão da definição e da padronização dos termos relativos ao campo da medicina do trabalho permaneceu como uma questão aberta, sem definições únicas, de forma que, dependendo da linha de pensamento dos atores envolvidos, optava-se pelo uso mais constante e muitas vezes de forma mesclada, dos termos medicina do trabalho e/ou higiene do trabalho. Ilustrativo desta questão é o depoimento do médico Hugo Firmeza acerca do uso das diferentes denominações:

\begin{abstract}
Já certa vez tivemos ocasião de criticar a denominação oficial de 'médicos do trabalho' que no Brasil é dada aos que têm por atribuição a higiene do trabalho. E dissemos: estes são 'higienistas do trabalho'. 'Médicos do trabalho' são os da previdência social, pois são eles os que exercem realmente a clínica do trabalho, no contato constante e obrigatório que têm com os trabalhadores, assistindo-os em todas as suas doenças e em todos os seus acidentes; 'médicos do trabalho' são os médicos de empresas, que atendem aos empregados e conhecem os locais em que estes têm sua atividade e os métodos de trabalho em que se ocupam..$^{38}$
\end{abstract}

Era a medicina do trabalho uma especialidade que estava se consolidando, sendo fundamental, portanto, as disputas e lutas por autoridade, legitimidade, reconhecimento e prestígio dos atores que a estavam construindo, das suas falas e dos lugares de onde falavam. Considero, então, esses médicos e higienistas do trabalho não como grupos que possuíam opções conceituais ou mesmo interesses muitos diversos, mas sim, como atores que estavam lutando por reconhecimento nos diferentes lugares que ocupavam: os médicos do trabalho, no MTIC e os higienistas do trabalho, no Ministério da Educação e Saúde (MES).

$\mathrm{O}$ artigo de Gerald Markowitz e David Rosner sobre a silicose e a questão da incapacitação dos doentes no período de 1930 a 1960, também levantou várias pistas para a nossa análise na medida em que evidenciou a teia de diferentes interesses dos atores envolvidos com a discussão e consolidação da silicose como doença relacionada ao trabalho. ${ }^{39}$ Eram médicos clínicos, médicos do Estado, eram

38 FIRMEZA, Hugo "Medicina do trabalho na previdência social” (Palestra realizada no Instituto de Aposentadoria e Pensões dos Comerciários). Medicina e Engenharia do Trabalho, 3 (2), junho, 1957, p. 28.

39 MARKOWITZ, Gerald and ROSNER, David. "The illusion of medical certainty: Silicosis and the Politics of Industrial Disability, 1930-1960”. In: ROSENBERG, Charles \& GOLDEN, Janet (orgs.). Framing Disease. Studies in Cultural History. New Brunswick, New Jersey: Rutgers University Press, 1992, p. 185-205. Sobre silicose ver também o instigante artigo de Angela Vergara, “The Recognition of Silicosis: Labor Unions and 
juízes, empresários, sindicalistas, trabalhadores, todos emaranhados em uma grande disputa.

Os debates sobre a relação doença e trabalho têm relevância no conjunto da produção desses especialistas e é um ótimo exemplo da riqueza da discussão médica e jurídica que envolve o processo de definição dos conceitos de doenças profissionais e doenças do trabalho. Ao longo desse processo diferentes grupos sociais manifestam e defendem seus diversos interesses, diante dos quais o Estado apresenta diferentes agendas políticas, nos possibilitando tomar as doenças do trabalho como um objeto para a análise da história da medicina do trabalho, bem como da história política, econômica e social do país no período de 1920 a 1950.40

Os estudos e inquéritos sobre a relação entre condições de trabalho e saúde e, particularmente, acerca das doenças profissionais (as inerentes ou peculiares a determinada atividade ou função), eram questões fundamentais da agenda desses especialistas. Para tanto era necessário enfrentar discussões quando buscavam definir o que seria uma moléstia do trabalho, uma doença do trabalho, uma moléstia profissional, uma doença profissional típica, uma doença profissional atípica, uma tecnopatia, uma mesopatia, definições estas que foram sendo definidas ao longo do processo de constituição do campo. Esse conjunto de termos e conceitos, que foram sendo elaborados em torno da relação do trabalho com a doença, é, a nosso ver, bastante expressivo no processo de construção do conceito chave de "doença do trabalho", isto é, da necessidade de circunscrever a abrangência do mesmo, do que seria e do que não seria abarcado pela definição.

\section{Leis de Acidentes e Doenças do Trabalho no Brasil}

A partir de agora vamos analisar com mais detalhes as leis de acidentes e doenças do trabalho no Brasil nas primeiras décadas do século XX. A já referida primeira Lei de Acidentes do Trabalho no Brasil, o Decreto $n^{\circ} 3.724$ de 1919, incluía na sua definição de acidentes do trabalho, as "moléstias" contraídas exclusivamente pelo exercício do trabalho. ${ }^{41}$ Naquele contexto, só eram abrangidas as doenças posteriormente definidas como doenças profissionais, exclusivas do exercício do trabalho, da natureza específica do mesmo, como por exemplo as intoxicações por substâncias, não considerando as doenças decorrentes das condições de trabalho. Os juristas e especialistas, que se dedicaram ao estudo e avaliação desta lei, criticavam o fato de não existirem capítulos dedicados à questão preventiva.

O médico Afrânio Peixoto, em estudo de 1926, dedicado ao tema da medicina legal - uma de suas especialidades -, analisa a lei de 1919 criticando o fato de só serem consideradas acidentes do trabalho "as moléstias exclusivas do exercício do trabalho". Ressalta ser o campo das doenças do trabalho um campo em aberto, ao qual deveriam se dedicar vários especialistas com o objetivo de estudar as doenças profissionais e as indiretamente profissionais, na medida em que as nossas leis não deveriam ser meras cópias das leis estrangeiras:

Physicians in the Chilean Copper Industry". Bulletin of the History of Medicine, 2005, volume 79, p. 723-748. 40 ALMEIDA, Anna Beatriz de Sá. "As parcelas (in)visíveis da saúde do trabalhador: uma contribuição da medicina do trabalho no Brasil (1920-1950)". (Tese de Doutorado em História, Universidade Federal Fluminense, Niterói, 2004); "De moléstias a doenças profissionais: uma contribuição ao estudo das doenças do trabalho no Brasil”. (Dissertação de Mestrado (História), Universidade Federal Fluminense, Niterói, 1994).

41 Decreto $\mathrm{n}^{\circ} 3.724,15$ de janeiro de 1919. 
Haveria entre nós por fazer este estudo das doenças profissionais dos nossos meios industriais, fábricas, usinas, oficinas, empregos diversos; causas de irritações; (...) infestações e infecções diversas; desde as de caráter diretamente profissional, como o carbúnculo dos que tratam couros e reses contaminados, o mormo dos cavalariços, a opilação e a malária dos trabalhadores rurais, até, a tísica dos mineiros, dos carteiros, dos tipógrafos, das lavadeiras etc., indiretamente, mas inegavelmente profissional ... ${ }^{42}$

Já a Lei de Acidentes do Trabalho de 1934, que substituiu a lei de 1919, ampliava a definição de acidente de trabalho, considerando-o "toda lesão corporal, perturbação funcional ou doença produzida pelo acidente de trabalho ou em consequência dele". Com relação às doenças profissionais, afirmava pelo seu Parágrafo $1^{\circ}$ :

São doenças profissionais, para os efeitos da presente lei, além das inerentes ou peculiares a determinados ramos de atividade, as resultantes exclusivamente do exercício do trabalho, ou das condições especiais ou excepcionais em que o mesmo for realizado, não sendo assim consideradas as endêmicas quando por elas forem atingidos empregados habitantes da região. ${ }^{43}$

Em relação às inerentes e peculiares, não havia muita divergência, na medida em que era da responsabilidade do MTIC organizar a relação das mesmas, baseandose em grande parte nas indicações da Organização Internacional do Trabalho (OIT). ${ }^{44}$ Neste grupo estavam inclusas as doenças causadas pelo fato de se trabalhar diretamente com substâncias tais como chumbo, fósforo, sílica, entre outras. Por outro lado, a lei abria campo também para considerar as doenças profissionais atípicas, as chamadas mesopatias, provenientes de determinadas condições em que o trabalho fosse realizado. Cabia provar a relação de causalidade entre o trabalho e a doença, terreno bastante propício às mais diversas interpretações, no qual tinham espaço as ações relativas a indenizações por acometimento de tuberculose e de outras doenças não inerentes e peculiares ao trabalho.

$\mathrm{Na}$ Lei de Acidentes de Trabalho de 1944 estavam presentes, tal como na lei de 1934, as doenças resultantes das condições de execução do trabalho, o que é considerado por alguns como uma "brecha" que permitiria, por exemplo, considerar-se a tuberculose em um operário têxtil como doença do trabalho, na medida em que fosse comprovada a relação causa e efeito entre o exercício do trabalho e a doença:

(...) como doenças, para os efeitos desta lei, entendem-se, além das chamadas profissionais - inerentes ou peculiares a determinados ramos de atividades -, as resultantes das condições especiais ou excepcionais em que o trabalho for realizado..$^{45}$

Cada vez mais, os trabalhos e pesquisas voltavam-se à identificação de novas substâncias tóxicas, presentes no processo de trabalho, e que poderiam ser reconhecidas como causadoras de doenças inerentes a uma determinada

42 PEIXOTO, Afrânio; FAVERO, Flamínio; RIBEIRO, Leonídio. Medicina legal dos acidentes do trabalho e das doenças profissionais. Rio de Janeiro: Livraria Francisco Alves, 1926, p. 109.

43 Decreto $n^{\circ} 24.637$ de 10 de julho de 1934.

44 A Organização Internacional do Trabalho (OIT) foi criada pela Conferência de Paz após a Primeira Guerra Mundial, tendo a sua Constituição se convertido na Parte XIII do Tratado de Versalhes.

45 Decreto-Lei ${ }^{\circ} 7.036$ de 10 de novembro de 1944. 
profissão. Cada vez mais, restaria àquelas doenças que não eram tipicamente profissionais, mas sim, decorrentes das condições de trabalho, como era o caso da tuberculose, o espaço da excepcionalidade, tanto nos debates médicos como nos processos jurídicos ao longo do tempo.

Os debates no campo da medicina do trabalho, e mais especificamente, das "doenças do trabalho" não ocorreram exclusivamente por questões científicas ou nos espaços científicos, mas estiveram sempre inseridos em contextos sociais mais amplos, envolvendo atores diferenciados. ${ }^{46}$ Neste quadro mais amplo, formulavam-se políticas sociais e organizavam-se instituições públicas e privadas dirigidas a definir, constituir e atuar no campo da medicina do trabalho.

Esses estudiosos das doenças profissionais, de uma maneira geral, estavam bastante articulados com a produção científica estrangeira e com as resoluções e recomendações das organizações internacionais, como, por exemplo, da OIT. Todo esse conhecimento era acrescido aos estudos próprios dos nossos especialistas que o aplicavam à realidade local e específica tanto das regiões quanto das atividades exercidas. Em outras palavras, a questão da saúde do trabalho era um tema com relativo destaque naquele momento, sendo os estudiosos brasileiros contemporâneos nesse debate.

Destacavam-se do corpo de artigos publicados, aqueles dedicados ao estudo do grau de insalubridade de determinadas indústrias e atividades. De uma forma geral, estes eram resultantes de trabalhos e inquéritos realizados pelos técnicos do MTIC, muitas vezes servindo de embasamento à elaboração de normas técnicas e de legislação trabalhista. Nesses estudos destacavam-se as atividades e indústrias geradoras de poeiras, tais como a cerâmica, as minas, vidros, indústria têxtil, entre outras. O trabalho com agentes tóxicos também era alvo de diversas colocações e normatizações, dado o índice de intoxicações e de doenças dele resultantes.

Através de seus estudos e levantamentos, ao mesmo tempo em que se mantinham atualizados com a produção internacional sobre a questão, esses médicos iam identificando e classificando o campo daquelas que viriam a ser denominadas "doenças profissionais". Cada vez mais, restaria àquelas doenças que não são tipicamente profissionais, mas sim decorrentes das condições de trabalho, como era o caso da tuberculose, o espaço da excepcionalidade, tanto nos debates médicos como nos processos jurídicos.

Se para os trabalhadores era clara a relação entre o acometimento pela doença e as precárias condições de trabalho e de vida, estando o combate à mesma vinculado à melhoria destas condições (diminuição da jornada de trabalho, melhores salários, condições higiênicas de trabalho e habitação etc.), para os empresários, reconhecer a relação da tuberculose com a fadiga, significava detonar o "caos" social, possibilitando a inversão total da ordem, alterando com "perigo" a relação capital \& trabalho. ${ }^{47} \mathrm{Em}$ meio a esse "embate" e inseridos no mesmo, os meios médico e jurídico foram constituindo "saberes", formulando considerações e propostas de enfrentamento à "peste branca”.

46 Para analisar a produção sobre as doenças profissionais entre os médicos do trabalho, selecionamos manuais de medicina e higiene do trabalho e artigos publicados na Revista do Trabalho, no Boletim do Ministério do Trabalho, Indústria e Comércio, na Revista Médica do Trabalho e na revista Medicina e Engenharia do Trabalho, sendo estas últimas as primeiras publicações especializadas do campo da medicina do trabalho localizadas ao longo da nossa pesquisa.

47 Ver neste sentido o trabalho de: COTTEREAU, Alain. "La tuberculose: maladie urbaine ou maladie de l'usure au travail”. Sociologie du Travail, IV-VI, 1978. Nesse artigo o autor fornece interessantes aportes à reflexão da relação tuberculose e trabalho, observando, com base em fontes, tanto do movimento operário, como das estatísticas e discursos médico-sanitários, o perigo à ordem social que resultaria do reconhecimento da relação entre a fadiga industrial e a doença. 


\section{Trabalhadores tuberculosos em julgamento}

A tuberculose seria ou não considerada uma doença do trabalho e, portanto, motivo de indenizações? Esta questão estava inserida num debate mais amplo que envolvia a delimitação e a definição do campo das "doenças do trabalho", ou seja, da criação de uma especialidade de saber e de um campo da medicina - a medicina do trabalho - e, também, de um campo do direito, o Direito do Trabalho.

Tanto a Revista do Trabalho como o Boletim do Ministério do Trabalho, Indústria e Comércio possuíam seções dedicadas à jurisprudência, várias ações referentes a processos julgando casos de tuberculose como doença do trabalho, assim como os compêndios de jurisprudência, os manuais de Direito do Trabalho e as revistas especializadas em Direito do Trabalho.

Como vimos anteriormente, as Leis de Acidentes do Trabalho de 1934 e de 1944, guardadas as suas diferenças, equipararam as doenças profissionais aos acidentes do trabalho e as dividiram em dois grupos: as ditas profissionais, inerentes ou peculiares a determinados ramos de atividade e as resultantes das condições especiais ou excepcionais em que o trabalho fosse realizado. 0 primeiro grupo, as inerentes ou peculiares a determinados ramos de profissão, tais como as intoxicações por chumbo e a silicose constantes da relação elaborada pelo MTIC, estariam isentas da necessidade de comprovação da ligação entre o trabalho e a doença. No segundo grupo, as doenças resultantes das condições do trabalho (nesse conjunto incluem-se os casos de indenização por doenças como a tuberculose e hérnia, por exemplo) era necessário comprovar-se o nexo entre o trabalho e a deflagração da doença.

Era exatamente neste grupo das doenças resultantes das condições do trabalho que se enquadravam os julgamentos dos processos de tuberculose. Acompanhando a jurisprudência sobre os mesmos, pudemos observar as diferentes argumentações e posicionamentos das partes envolvidas nas ações. Alegavam os empregados ou mesmo seus familiares, na maior parte das ações, ter sido a doença contraída em virtude das condições do trabalho e solicitavam, dessa forma, indenização de acordo com a legislação que regula os acidentes de trabalho. A relação tuberculose e trabalho era clara e presente no universo desses trabalhadores, tal como o era entre os trabalhadores das primeiras décadas. Todos eles, ao longo de décadas, consideraram a doença adquirida, uma espécie de "injustiça" sofrida, contra a qual seria possível, nesse momento, o recurso à justiça, ao campo dos direitos sociais.

De outro lado, os empresários e as firmas seguradoras de um modo geral defendiam-se das acusações, alegando ser a tuberculose uma doença social, ligada às condições e hábitos de vida fora do espaço do trabalho, não sendo possível provar que a mesma decorria do exercício do trabalho. Os juízes, por sua vez, preocupavam-se em analisar a relação de causalidade existente nos processos de indenização e sempre destacavam que, não estando a tuberculose incluída no campo das doenças inerentes ou peculiares a determinados ramos, havia que se analisar caso por caso. Baseavam então suas sentenças nos laudos dos peritos, na situação de saúde do trabalhador ao ingressar nos estabelecimentos e nas informações das testemunhas.

As sentenças dos juízes refletiam, em muito, a polêmica do tema. Havia aqueles que não consideravam possível que o trabalho fosse responsabilizado pelo acometimento de uma doença infectocontagiosa de caráter social. Outros justificavam que, tendo o operário ingressado no serviço com boas condições 
de saúde e comprovando-se as precárias condições de trabalho e do ambiente indicadas pelo trabalhador como causas do seu adoecimento, estaria comprovado o nexo de causalidade entre o trabalho e a doença.

Porém cabe destacar que neste espaço tanto os médicos-legistas, quanto os médicos do trabalho e os tisiólogos atuavam como coadjuvantes. A luta, quando chegava ao cenário do tribunal, não mais estava sendo travada exclusivamente no campo do saber médico, havendo também outros interesses conflitantes em jogo. Era uma luta entre trabalhadores e patrões travada na arena jurídica, com grande destaque para a atuação e decisão do juiz, este o ator principal, por excelência.

De uma maneira geral, as decisões favoráveis ao julgamento da tuberculose como doença causada pelo trabalho, buscavam responsabilizar o empregador pelo estado de saúde dos seus trabalhadores desde o momento em que os mesmos ingressavam no serviço. Reconheciam-se os prejuízos de determinadas condições de trabalho, e até mesmo de determinados processos de trabalho, à saúde do trabalhador, e neste sentido, urgia compensá-lo pela injustiça sofrida, sendo este um ônus a ser pago pelo empregador.

Cada processo julgado tornava-se peça fundamental na construção da jurisprudência sobre o assunto, funcionando como referência aos magistrados da área, sendo de fundamental importância para os juízes a observância dos procedimentos adotados na questão que construía a tradição de um novo ramo do direito no Brasil. Era fato comum que os acórdãos apresentassem várias citações e referências à jurisprudência tanto de âmbito nacional como internacional. Nos próprios textos das sentenças, os juízes e relatores faziam constantes referências à dificuldade do julgamento dos casos. Daí a importância de pautarem-se os julgamentos pela jurisprudência já produzida, recorrendo-se constantemente a análises de especialistas tanto em infortunística como em medicina do trabalho e tisiologia.

Selecionamos, nos periódicos consultados e nos compêndios de jurisprudência, um conjunto de ações de acidente do trabalho, as quais reivindicavam indenização por tuberculose consequente do trabalho. Deste grupo de ações, mais da metade das sentenças foram julgadas favoravelmente aos empregados. Podese aventar que o tipo de seleção feita pelos periódicos e compêndios consultados é indicadora do posicionamento dos articulistas das revistas e de uma possível tendência dos julgamentos.

Em sentença proferida em 26/06/1941, o Juiz de Direito Tácito Morback, da Vara dos Acidentes de Trabalho de São Paulo, ao julgar a solicitação do foguista e calandrista de uma indústria de condutores elétricos que afirmava ter contraído tuberculose em função das precárias condições do seu trabalho (variações de temperatura, aspiração de poeiras etc.) fez a seguinte consideração: "A jurisprudência tem firmado o princípio de que a tuberculose, embora não esteja inscrita entre as doenças profissionais, em certas circunstâncias assim deve ser considerada". ${ }^{48}$ Finalizando a sentença, o juiz destacou que as más condições de trabalho vinham sendo responsáveis pela eclosão da tuberculose em grande número de operários.

Também o laudo técnico dos peritos era peça fundamental para que fosse comprovado o nexo de causalidade entre a doença e o trabalho. Caberia a eles analisar se as condições de trabalho alegadas pela vítima eram reais e suficientes para o desenvolvimento da moléstia. Acrescente-se à jurisprudência e aos laudos dos peritos, o papel desempenhado pelas provas testemunhais. Em muitos dos

48 Revista do Trabalho, agosto, 1941, p. 452. 
casos analisados, a decisão final do juiz fora pautada em provas testemunhais que chegavam até mesmo a questionar os laudos técnicos. Os textos das sentenças chegavam a insinuar que o ambiente e as próprias condições de trabalho poderiam ter sofrido alterações em função das vistorias realizadas, daí as diferenças entre as descrições das testemunhas, normalmente operários da mesma seção do acidentado, e os laudos dos peritos.

Outro elemento bastante presente nas sentenças era a prática de justificar os votos recorrendo à produção médico-científica sobre a questão. Citavamse especialistas em medicina do trabalho, em tisiologia e em infortunística, ${ }^{49}$ brasileiros e estrangeiros. Entre os brasileiros, Araújo de Castro, Afrânio Peixoto, Barros Barreto e Flamínio Fávero eram os mais destacados. Referências a médicos especialistas italianos e franceses também compunham os textos de diversas sentenças. Desta forma, os especialistas em medicina do trabalho e em medicina legal embasavam as considerações e até mesmo as decisões jurídicas no campo do direito do trabalho, demonstrando a inter-relação entre os saberes médicos e jurídicos.

Elucidativo desta interação, é o processo movido por um trabalhador, em 1941, que por lidar com raspagem de tintas, alegou ter desenvolvido uma pneumoconiose que posteriormente evoluiu para tuberculose em função do ambiente de trabalho, carregado de pós suspensos. O empregado veio a falecer no curso do processo, mas a família prosseguiu com a ação. Houve divergência entre os laudos médicos: um apresentava como causa da morte uma tuberculose galopante e outro apontava a tuberculose como uma evolução da pneumoconiose adquirida em função do trabalho executado.

Ao iniciar o texto do acórdão, o desembargador relator destacou que, mesmo sem ser um especialista em medicina e infortunística, era de fundamental importância para um juiz ter noções básicas sobre essa área do conhecimento para poder emitir seus julgamentos. Nesse sentido, recorreu a trabalhos médicos de especialistas estrangeiros sobre pneumoconioses, e citou o laudo apresentado por um famoso radiologista, médico da Faculdade de Medicina, que diagnosticava a pneumoconiose do operário como proveniente do exercício do trabalho. Finalizando, o relator considera ter sido o ambiente do trabalho o instrumento de 'êxito letal', inicialmente pela pneumoconiose que abriu caminho para que, posteriormente, a infecção tuberculosa se instalasse em terreno minado, levando o operário a "sucumbir vítima de moléstia contraída no trabalho", confirmando a decisão favorável ao operário. ${ }^{50}$

Encontramos indícios da permanência destas práticas de julgamento ao analisarmos um processo, julgado em março de 1963, que recorreu ao debate no meio médico nas décadas de 1940 e 1950, com o objetivo de contextualizar a questão e justificar a decisão tomada. O caso em foco é um novo julgamento do processo de um operário que solicitou indenização por tuberculose adquirida em virtude do trabalho com vapores irritantes e tóxicos. O processo foi julgado improcedente em primeira instância e o operário solicitou revisão da sentença.

O texto do acórdão traça um histórico do caso e destaca que os dois peritos do processo entenderam que a tuberculose apresentada não tinha relação com o trabalho executado tomando por base as conclusões congresso realizado em Saranak, EUA, em 1941. Nesse congresso, os tisiólogos ali reunidos concluíram que

49 A infortunística pode ser definida como o conjunto de regras e princípios adotados para o estudo dos riscos, acidentes e doenças decorrentes das atividades profissionais.

50 Cf. Revista do Trabalho, dezembro, 1941, p. 683-685. 
só seria a tuberculose considerada doença profissional quando fosse resultante diretamente de contágio, silicose ou traumatismo. Com base nos laudos desses peritos é que o pedido de indenização do operário foi julgado improcedente em primeira instância. Prossegue reportando-se também à mesa redonda 0 Tuberculoso em Face da Lei, promovida pela Associação Paulista de Medicina em 1958, que, de uma certa maneira, chegara à mesma conclusão do Congresso de Saranak, apesar dos posicionamentos divergentes do médico-legista Flamínio Fávero. Com base nas críticas de Flamínio Fávero com relação à simplicidade do posicionamento dos tisiólogos frente à questão, (contágio direto ou trabalho com sílica), o parecer do tribunal questionou os laudos dos peritos.

A jurisprudência, contudo, tem abrandado muito essas conclusões dos peritos médicos, concluindo que, embora o trabalho, fora daquelas condições e casos especiais que caracterizam moléstia profissional típica, não constitua ou não contribua para a evolução ou aparecimento da tuberculose, sem causa externa comprovada, e verificando-se condições adversas e anormais no ambiente de trabalho do doente, este ambiente de trabalho constitui uma concausa na eclosão da moléstia. ${ }^{11}$

Destacou-se, dessa forma, a debilitação orgânica causada pelo trabalho e pelo ambiente em que o mesmo era desenvolvido (exaustão insuficiente, ar superaquecido, vapores tóxicos e irritantes), como uma concausa ao desenvolvimento da tuberculose, reconhecendo ser a tuberculose em questão uma doença do trabalho, portanto indenizável. A decisão do tribunal foi dar provimento ao recurso do operário, com base na ideia de concausa do trabalho, desconsiderando, de certa forma, os próprios pareceres dos peritos. Como podemos observar a principal argumentação utilizada pelos trabalhadores para justificar esse tipo de ação judicial era, quase sempre, ressaltar a precariedade das condições a que ficavam expostos durante o trabalho, tais como umidade, ventilação, alta variação de temperatura, exposição a chuva, ventos, inalação de poeiras etc.

Encontramos ações que, em função da grande polêmica gerada, foram palco de votos divergentes entre os próprios membros do tribunal. É o exemplo do operário de caldeira de fusão de ferro gusa que, em 1939, alegou ter contraído tuberculose em virtude das suas condições de trabalho. O processo foi objeto de certa polêmica na medida em que não houve unanimidade nos votos dos ministros do Tribunal de Apelação. Um desembargador, que teve seu voto vencido, julgou pela improcedência da ação que afirmava ter sido a tuberculose contraída no trabalho, pela nulidade de provas neste sentido. Destacava não ter havido outro caso da doença no estabelecimento e acrescentava que a mesma poderia ter sido contraída fora do ambiente de trabalho (resfriados, noites mal dormidas etc.). ${ }^{52}$

Por outro lado, a decisão final que julgou procedente a ação, baseou-se nas informações prestadas pelo médico-perito Flamínio Fávero, destacando a autoridade de seu nome nestas questões. De acordo com o laudo do referido médico-legista, a despeito de os operários terem passado a trabalhar em prédio novo e mais arejado, não se eliminou completamente os riscos, pois ainda persistia o trabalho com terra de fundição que, antes de ser umedecida, desprendia poeiras. Portanto, no prédio velho, essas condições de trabalho eram muito mais desfavoráveis. Além disso, o fato de que, ao ingressar no trabalho, o operário

51 BRAGA, Marigildo de Camargo. Moléstias profissionais e doenças do trabalho. São Paulo: Aries, 1965, p. 250. 52 Cf. Revista do Trabalho, novembro, 1939. 
gozava de boas condições de saúde, segundo informações de sua carteira de saúde, eliminava a possibilidade de invocar as condições pessoais do mesmo para eximir o patrão da responsabilidade.

Como já apontamos anteriormente, eram peças básicas para a decisão dos juízes os laudos técnicos, as provas testemunhais e o estado de saúde do operário ao ingressar no trabalho. Este último item era bastante apontado nos textos que afirmavam ser obrigação do empregador, ao contratar os seus empregados, certificar-se do seu estado de saúde (higidez) e que, no momento em que este assim não procedesse estaria assumindo os respectivos riscos. Destacava-se o papel das já referidas carteiras de saúde no ato de julgamento. Criadas em 1932, como condição preliminar ao exercício do trabalho, funcionavam como "prova" do estado de saúde do empregado ao ingressar no estabelecimento, contrapondose, em certas situações, à argumentação comum aos empregadores de que o trabalhador já havia ingressado doente.

Ilustrativo, nesse sentido, é o caso do pedreiro que, em 1940, afirmava ter contraído tuberculose em função do trabalho dentro de valetas, com água até os joelhos, aliado à exaustão física. Recorre o empregador alegando que o empregado já era portador da doença quando foi admitido no serviço. O acórdão foi desfavorável ao agravo do empregador, concluindo que:

não conseguiu a agravante provar que o operário, ao ser admitido a seu serviço, já sofresse da referida moléstia. A presunção é que não sofresse, sem o que não teria sido expedida a seu favor a carteira de saúde. Além disso, deve o empregador, ao contratar o obreiro, certificar-se do seu estado de higidez ...53

Da mesma forma, a operária de uma fábrica de tecidos que alegou ter contraído tuberculose devido ao trabalho desenvolvido em ambiente abafado, sem ventilação e com grande número de operários, foi isentada de qualquer responsabilidade pela doença. Afirmava ser uma pessoa de "costumes morigerados", isto é, pessoa de "bons costumes" que, ao ingressar no trabalho, não apresentava problemas de saúde. A proprietária do estabelecimento contestou as alegações da operária afirmando não ser real a descrição do ambiente de trabalho por ela feita, tanto que não havia outros casos de tuberculose entre os demais operários. Com relação à operária, insinuou que "o estado de saúde da autora alterou-se depois de ter ela contratado casamento e dado à luz um filho".54

Mais uma vez a pretensão foi a de responsabilizar vítima, tornando-a causadora do aparecimento da doença. Porém, as provas testemunhais e o laudo dos peritos foram suficientes para considerar as precárias condições do trabalho como as responsáveis pela doença, embasando desta forma a decisão do juiz pela procedência da ação.

De uma maneira geral, as decisões favoráveis ao julgamento da tuberculose como doença causada pelo trabalho, buscavam responsabilizar o empregador pelo estado de saúde dos seus trabalhadores desde o momento em que os mesmos ingressavam no serviço. Reconheciam-se os prejuízos de determinadas condições de trabalho e, até mesmo, de determinados processos de trabalho à saúde, e neste sentido, urgia compensar o trabalhador pela injustiça sofrida, sendo este um ônus a ser pago pelo empregador.

Do conjunto das ações julgadas selecionadas, havia as que não consideravam

53 Revista do Trabalho, maio, 1940, p. 248.

54 Revista do Trabalho, abril, 1941, p. 53. 
a tuberculose uma doença contraída em função do trabalho. De uma forma geral, justificavam seus pareceres contrários aos pedidos de indenização, alegando não ter ficado suficientemente demonstrada a relação entre causa (condições de trabalho) e efeito (tuberculose). Neste sentido, a doença poderia ter sido contraída em decorrência das condições de vida do próprio trabalhador.

Este foi o caso de um estanhador, em 1937, que tendo trabalhado por 20 anos para a Companhia Brasileira de Usinas Metalúrgicas atribuíra a tuberculose pulmonar por ele adquirida às condições de trabalho. O laudo dos peritos, tendo por base a Lei de Acidentes do Trabalho de 1934, argumentava que a profissão não fora causa direta e exclusiva da doença. ${ }^{55}$ Prosseguia o texto, destacando não existir referência de nenhum outro caso de tuberculose entre os companheiros do estanhador, o que dificulta considerá-la moléstia da profissão. Negava-se a possibilidade de indenização do operário, apesar de reconhecer-se o papel indireto da profissão no agravamento da doença.

Outro caso relata a situação de um padeiro que tendo trabalhado junto ao forno e estando sujeito ao calor excessivo e a respiração de cinzas, alegara ter contraído tuberculose em função do trabalho. O primeiro julgamento do caso foi favorável à solicitação do padeiro, tendo sido condenado o empregador ao pagamento de indenização. Este recorreu da sentença, questionando a decisão, ocasionando um novo julgamento. O relator do acórdão inicia fazendo considerações sobre a doença tuberculose, suas formas de contágio, recorrendo, para tanto, a especialistas italianos. Ressaltava o relator a dificuldade de classificar a tuberculose como doença profissional:

\footnotetext{
(...) muito mais difícil será classificar a tuberculose como doença profissional, quando não houver no lugar do trabalho foco infectante e a moléstia possa ter outras causas, como, por exemplo, superinfecção por contato como pessoas da família, exaurimento de energias orgânicas, más condições de habitação ou imprudências praticadas fora do trabalho. ${ }^{56}$
}

Concluindo, afirma que o trabalho do padeiro poderia ter sido uma causa coadjuvante, mas não havia provas suficientes para considerá-lo causa determinante da moléstia. Desta forma, reconhece-se o agravo do empregador, considerando a ação julgada anteriormente improcedente, negando-se, a partir de então, o direito do empregado à indenização. Alteravam-se as peças do jogo, de forma que os próprios trabalhadores, pelas suas condições de vida, tornavamse, eles próprios, responsáveis pela doença. Responsabilizam-se desta forma as "imprudências praticadas fora do trabalho" e, ao mesmo tempo, apontava-se para o exaurimento orgânico, não se levando em conta o papel fundamental do trabalho, e das condições em que o mesmo era exercido, em tal esgotamento.

\section{Enfim, a tuberculose era responsabilidade de quem?}

"A tuberculose é uma doença social", esta era uma afirmação recorrente, tanto na defesa dos acusados, os patrões, como nas sentenças dos juízes, e como tal, não caberia responsabilizar os patrões pelo seu acometimento. Não teria havido algum caso de tuberculose na família do operário? Quando ingressou no serviço,

55 Revista Forense, março, 1937, p. 514.

56 Revista do Trabalho, fevereiro, 1942, p. 46. 
gozava realmente o trabalhador de boa saúde? Era o trabalhador uma pessoa de "bons costumes" ou havia indícios de ter uma "vida desregrada", "imprudente"?

A reivindicação de Arlete, operária de uma lavanderia que afirmava ter contraído tuberculose em função de transportar roupas úmidas e trabalhar em piso de cimento, foi julgada improcedente posto que a perícia realizada considerou as condições de trabalho dentro das normas da técnica e da higiene e testemunhas descreveram a vítima como "moça franzina, de constituição enfermiça, dada a desregramento sexual e descuidada da própria saúde". ${ }^{77}$ O juiz finalizou sua sentença, demonstrando profundo desgosto frente à impossibilidade legal de atender às reivindicações da operária: "[julgo] improcedente a ação, malgrado a funda tristeza que nos toca de não poder amparar a pretensão de Arlete". ${ }^{8}$

Assim, eram os trabalhadores diagnosticados no seu dia a dia, em busca de provas que os responsabilizassem individualmente pelas suas condições de saúde. No discurso dos industriais, de alguns juízes e de higienistas, as imagens do trabalhador e da suas condições de vida estavam associadas à promiscuidade, doença e sujeira. Os próprios trabalhadores ao apresentarem seus argumentos e suas justificativas para solicitar o amparo da justiça, não deixavam de afirmar serem pessoas de bons costumes, decentes e que gozavam de boa saúde quando foram admitidos. Era o 'trabalho' de reconstrução da sua própria imagem e de afirmação do seu próprio discurso, contando para tanto, por muitas vezes, com o auxílio dos advogados. Tal estratégia demonstrava o conhecimento da imagem sobre eles construída e a necessidade muitas vezes de sobrepor outra imagem.

Recebido em 10/02/2015 Aprovado em 23/08/2015 